\title{
Cal dolomítica: o passado e o presente
}

\author{
Dolomitic lime: the past and present
}

\section{Antonio Santos Silva}

\section{Resumo}

A

cal aérea é um ligante com grande durabilidade, como atestam inúmeros vestígios arqueológicos da época romana e não só. Quando é referido que uma determinada argamassa ou pintura mural foi executada com cal aérea, poucas vezes é descrito que ela é do tipo dolomítico. A escassez de referências a este tipo de ligante pode ser atribuída à menor disponibilidade de calcários dolomíticos. Porém, existem vários casos em Portugal, e em outros Países, da sua utilização que não parecem estar só associados aos principais recursos calcários. É reconhecido que em termos tecnológicos a sua produção requer menor temperatura de calcinação do que a necessária para a produção de cal calcítica. Este motivo, associado a propriedades de resistência à água, terá justificado o uso da cal dolomítica no passado, como atestam alguns exemplos de construções antigas, alguns dos quais são descritos brevemente neste artigo. Apesar desse passado, a cal dolomítica continua atualmente a ser desconhecida para a maioria dos membros da comunidade técnica e científica. Acresce que alguns resultados de caracterização são por vezes contraditórios, o que motiva algum receio da sua utilização. Este artigo visa desmistificar alguns preconceitos relacionados com uma eventual menor durabilidade da cal dolomítica, apresentando-se os mecanismos reacionais deste ligante e dos seus compostos de hidratação e de alteração, bem como alguns exemplos da utilização da cal dolomítica em monumentos Portugueses. Finalmente são apresentados resultados de caracterização física e mecânica deste ligante secular, que confirmam as suas características e que justificam o seu maior uso, nomeadamente em casos de conservação e restauro de argamassas em edificações históricas.

Palavras-chave: Cal. Argamassas. Durabilidade. Caracterização.

\begin{abstract}
Aerial lime is a binder with great durability, as attested by numerous archaeological remains from the Roman period and beyond. When it is reported that a particular mortar, or mural painting, was executed with aerial lime, it is rarely mentioned that this lime is a dolomitic type. The scarcity of references to this type of binder can be attributed to the lower availability of dolomitic limestone outcrops. However, there are several cases in Portugal, and in other parts of the world, where the use of dolomitic lime mortars do not seem to be associated only with the main limestone qualities. In technological terms, it is a known fact that the production of dolomitic lime requires a lower calcination temperature than that required for the production of calcitic lime. This fact, coupled with good water resistance properties, will have justified the use of dolomitic lime in the past, as some examples of ancient constructions attest, some of which are described briefly in this paper. Despite this past, dolomitic lime remains unknown to most members of the technical and scientific community. In addition, some characterization results are sometimes contradictory, which motivates misgivings about its use. This article aims to demystify some of the biases related to a possible lower durability of dolomitic lime, presenting the reactional mechanisms of this binder and its hydration and alteration compounds, as well as some examples of the use of dolomitic lime in Portuguese monuments. Finally, results of physical and mechanical characterization of this age-old binder are presented, confirming its qualities and justifying more widespread, especially in cases of conservation and restoration of historical mortars.
\end{abstract}

Recebido em 14/12/17

Aceito em 28/05/18 Keywords: Lime. Mortars. Durability. Characterization. 


\section{Introdução}

A descoberta do fogo e dos efeitos do calor nas propriedades dos materiais, nomeadamente nas argilas e nos calcários, fizeram com que o Homem primitivo descobrisse as características aglutinantes destes materiais em contacto com a água.

A cal foi durante vários séculos o principal tipo de ligante empregue, tirando partindo dos afloramentos calcários dispersos por todo o mundo, ou na ausência destes pela utilização de matéria-prima alternativa como conchas de moluscos (PANDA; MISRA, 2007) ou corais (GLEIZE et al., 2009), entre outras fontes de calcário.

As argamassas de cal provaram ser duráveis, considerando os testemunhos espalhados por todo o mundo, algumas com muitos séculos de utilização. De acordo com Maravelaki-Kalaitzaki, Bakolas e Moropoulou (2003), já no Período Minoico Recente (1580 a.C. - 1100 a.C.) utilizavam-se argamassas de cal misturadas com materiais pozolânicos. Mas foi no período do Império Romano (27 a.C. - 476 d.C.) que mais se inovou na utilização deste ligante. Esse aspeto não é indissociável do cuidado e a preocupação que os romanos tiveram com a seleção dos materiais, e que se traduziu, por exemplo, pela incorporação de fragmentos de produtos cerâmicos partidos oumoídos quando não dispunham de pozolanas naturais de qualidade e necessitavam que as argamassas fossem resistentes à ação da água. No entanto, com a descoberta no século XIX do cimento portland, a cal foi sendo progressivamente substituída nas construções, o que originou também problemas na conservação das construções históricas (VEIGA et al., 2001; PAPAYANNI, 2005).

Pese embora existam muitos trabalhos que atestam a durabilidade das argamassas de cal, poucas vezes é descrito que essa cal é do tipo dolomítico. Essa eventual escassez de referências a este tipo de ligante pode ser atribuída a uma menor disponibilidade de afloramentos geológicos de calcários dolomíticos. No entanto, existem vários casos em Portugal, como em outros países, que confirmam a utilização da cal dolomítica em argamassas e que demostram a sua durabilidade (DIEKAMP; ZONZETT; MIRWALD, 2008; SANTOS SILVA et al., 2010).

A cal dolomítica requer menor temperatura de calcinação do que a necessária para a produção de cal calcítica (CHEVER; PAVÍA; HOWARD, 2010). Este motivo, associado a propriedades de resistência à água, terá justificado o uso da cal dolomítica no passado, como atestam alguns exemplos de construções antigas que chegaram à atualidade.

Apesar desse passado, a cal dolomítica continua atualmente a ser desconhecida para a maioria dos membros da comunidade técnica e científica. Acresce que alguns resultados de caracterização são por vezes contraditórios, o que motiva algum receio da sua utilização. Neste artigo são por isso apresentados resultados de caracterização que procuram elucidar os aspetos negativos e positivos associados a este ligante secular, tendo como objetivo garantir o seu uso, nomeadamente em casos de conservação e restauro de argamassas históricas.

\section{Ciclo da cal dolomítica}

As rochas calcárias são constituídas essencialmente pelos minerais calcite $\left(\mathrm{CaCO}_{3}\right)$ e dolomite $\left(\mathrm{CaMg}\left(\mathrm{CO}_{3}\right)_{2}\right)$, podendo variar os teores, os quais influenciam o tipo de cal viva que se obtém após a calcinação do calcário calcítico (Equação 1) ou dolomítico (Equação 2), respetivamente.

$\mathrm{CaCO}_{3}+$ calor $\rightarrow \mathrm{CaO}+\mathrm{CO}_{2} \quad$ Eq. 1

$\mathrm{CaMg}\left(\mathrm{CO}_{3}\right)_{2}+$ calor $\rightarrow \mathrm{CaO}+\mathrm{MgO}+2 \mathrm{CO}_{2}$ Eq. 2

O termo "dolomite" provém de Dolomite Mountains nos Alpes, na região do Tirol na Áustria e norte da Itália, onde o calcário dessa região tem um alto teor em magnésio (HARTSHORN, 2012). A Norma Europeia EN 459-1 (INSTITUTO..., 2011) estabelece para a cal dolomítica um mínimo $80 \%$ (em massa) da soma de óxido de cálcio $(\mathrm{CaO})$ e óxido de magnésio (MgO), com um minímo de $5 \%$ de $\mathrm{MgO}$, enquanto a cálcica deverá ter um minímo de $70 \%$ da soma desses dois óxidos e um máximo de $7 \%$ em $\mathrm{MgO}$.

A cal viva (cálcica ou dolomítica), produto resultante da calcinação do correspondente calcário, é um produto extremamente perigoso pelo que deve ser extinta por adição água (processo de hidratação), obtendo-se a cal hidratada que, dependendo da quantidade de água adicionada, pode ser na forma de pó ou em pasta (Equações 3 e 4):

$\mathrm{CaO}$ (cal/óxido de cálcio) $+\mathrm{H}_{2} \mathrm{O} \rightarrow \mathrm{Ca}(\mathrm{OH})_{2}$ (portlandite)+ calor Eq. 3

$\mathrm{CaO}+\mathrm{MgO}$ (periclase/óxido de magésio) $+2 \mathrm{H}_{2} \mathrm{O}$ $\rightarrow \mathrm{Ca}(\mathrm{OH})_{2}+\mathrm{Mg}(\mathrm{OH})_{2}$ (brucite) + calor Eq. 4

O endurecimento da cal hidratada dá-se através da reação com o dióxido de carbono da atmosfera 
(processo de carbonatação), dando novamente origem a diferentes carbonatos consoante o tipo de cal (Equações 5 e 6):

$$
\begin{aligned}
& \mathrm{Ca}(\mathrm{OH})_{2}+\mathrm{CO}_{2} \rightarrow \mathrm{CaCO}_{3} \text { (calcite) }+\mathrm{H}_{2} \mathrm{O} \quad \text { Eq. } 5 \\
& \mathrm{Ca}(\mathrm{OH})_{2}+\mathrm{Mg}(\mathrm{OH})_{2}+2 \mathrm{CO}_{2} \rightarrow \mathrm{CaCO}_{3}+\mathrm{MgCO}_{3} \\
& \text { (magnesite) }+2 \mathrm{H}_{2} \mathrm{O}
\end{aligned}
$$

De notar que, na cal dolomítica, as reações de hidratação e de carbonatação ocorrem de forma muito mais lenta do que no caso da cal cálcica (VINAGRE, 2015), nomeadamente a reação de hidratação e a de carbonatação (HARTSHORN, 2012).

A carbonatação da cal dolomítica origina uma gama muito diversa e extensa de carbonatos de magnésio e de carbonatos básicos de magnésio, cuja formação vai depender da composição da cal utilizada, nomeadamente da quantidade de magnésio disponível, dos teores de $\mathrm{CO}_{2}$ e humidade no ar, e também da quantidade de água presente na argamassa. Entre os possíveis compostos cristalinos formados estão a hidromagnesite $\quad\left(\mathrm{Mg}_{5}\left(\mathrm{CO}_{3}\right)_{4}(\mathrm{OH})_{2} \cdot 4 \mathrm{H}_{2} \mathrm{O}\right)$, dipingite $\quad\left(\mathrm{Mg}_{5}\left(\mathrm{CO}_{3}\right)_{4}(\mathrm{OH})_{2} .5 \mathrm{H}_{2} \mathrm{O}\right)$, artinite $\quad\left(\mathrm{Mg}_{2}\left(\mathrm{CO}_{3}\right)(\mathrm{OH})_{2} \cdot 3 \mathrm{H}_{2} \mathrm{O}\right)$, nesqueonite $\left(\mathrm{Mg}\left(\mathrm{HCO}_{3}\right)(\mathrm{OH}) .2 \mathrm{H}_{2} \mathrm{O}\right)$, lansfordite $\left(\mathrm{MgCO}_{3} .5 \mathrm{H}_{2} \mathrm{O}\right), \quad$ unstite $\left(\mathrm{Mg}_{3} \mathrm{Ca}\left(\mathrm{CO}_{3}\right)_{4}\right)$ e a dolomite $\left(\mathrm{CaMg}\left(\mathrm{CO}_{3}\right)_{2}\right)$. Mas também há referência à presença de compostos amorfos de magnésio em argamassas de cal dolomítica (MONTOYA et al., 2003), formação atribuída a cal sobrecozida.

Os óxidos, hidróxidos e carbonatos de magnésio, mas também de cálcio, são compostos que apresentam alguma reatividade, nomeadamente a sais de sulfatos, o que tem gerado alguma controvérsia na utilização da cal dolomítica.

\section{Produtos de alteração da cal dolomítica}

O facto de nas cais dolomíticas as reações de hidratação e de carbonatação ocorrerem, como referido, com velocidade mais lenta torna-as, em comparação com as cais cálcicas, mais suscetíveis para reagirem com outras substâncias. Em particular, vários autores têm referido que a cal dolomítica em ambientes urbanos e industriais pode estar sujeita à sulfatação, podendo originar a formação de sais muito solúveis de sulfatos hidratados de magnésio (Equações 7 e 8), como a epsomite e a hexahidrite (ARIZZI, CULTRONE, 2001):

$\mathrm{Mg}(\mathrm{OH})_{2}+0.5 \mathrm{O}_{2}+6 \mathrm{H}_{2} \mathrm{O}+\mathrm{SO}_{2} \rightarrow \mathrm{MgSO}_{4} .7 \mathrm{H}_{2} \mathrm{O}$ (epsomite) $\quad$ Eq. 7

$\mathrm{Mg}(\mathrm{OH})_{2}+0.5 \mathrm{O}_{2}+5 \mathrm{H}_{2} \mathrm{O}+\mathrm{SO}_{2} \rightarrow \mathrm{MgSO}_{4} \cdot 6 \mathrm{H}_{2} \mathrm{O}$ (hexahidrite) $\quad$ Eq. 8

Segundo Diekamp et al. (2012), durante a formação dos sulfatos de magnésio existem três efeitos principais que causam dano:

(a) aumento de volume associado à formação de sulfato de magnésio a partir de um composto precursor (por exemplo, magnesite);

(b) mudança de volume associada à transição de fase epsomite-hexahidrite; $\mathrm{e}$

(c) lixiviação dos sulfatos de magnésio, após sua cristalização, devido à sua elevada solubilidade em água (Tabela 1), o que provoca a perda de material.

Os efeitos 1 e 2 podem criar altas pressões de cristalização levando à fissuração e desagregação do ligante.

Importante ainda realçar que numa argamassa de cal dolomítica as fases cálcicas (portlandite e calcite) também podem combinar-se com os sulfatos (Equações 9 e 10), contribuindo assim para o agravamento dos danos.

$$
\begin{array}{lr}
\mathrm{Ca}(\mathrm{OH})_{2}+0.5 \mathrm{O}_{2}+2 \mathrm{H}_{2} \mathrm{O}+\mathrm{SO}_{2} \rightarrow \mathrm{CaSO}_{4} \cdot 2 \mathrm{H}_{2} \mathrm{O} \\
(\text { gesso })+\mathrm{H}_{2} \mathrm{O} & \text { Eq. } 9 \\
\mathrm{CaCO}_{3}+0.5 \mathrm{O}_{2}+2 \mathrm{H}_{2} \mathrm{O}+\mathrm{SO}_{2} \rightarrow \mathrm{CaSO}_{4} .2 \mathrm{H}_{2} \mathrm{O}+ \\
\mathrm{CO}_{2} \text { Eq. } 10
\end{array}
$$

Tabela 1 - Valores de solubilidade em água (à temperatura ambiente) de alguns compostos em argamassas de cal

\begin{tabular}{l|c}
\hline \multicolumn{1}{c|}{ Composto } & Solubilidade em água $(\mathrm{g} / \mathbf{L})$ \\
\hline Epsomite $\left(\mathrm{MgSO}_{4} \cdot 7 \mathrm{H}_{2} \mathrm{O}\right)$ & 710 \\
Hexahidrite $\left(\mathrm{MgSO}_{4} \cdot 6 \mathrm{H}_{2} \mathrm{O}\right)$ & 660 \\
Gesso $\left(\mathrm{CaSO}_{4} \cdot 2 \mathrm{H}_{2} \mathrm{O}\right)$ & 0,24 \\
Magnesite $\left(\mathrm{MgCO}_{3}\right)$ & 0,14 \\
Portlandite $\left(\mathrm{Ca}(\mathrm{OH})_{2}\right)$ & 0,12 \\
Calcite $(\mathrm{CaCO} 3)$ & 0,013 \\
Brucite $\left(\mathrm{Mg}(\mathrm{OH})_{2}\right)$ & 0,006 \\
\hline
\end{tabular}


Pese embora esta situação, os resultados encontrados na literatura são muito contraditórios no que se refere à utilização de argamassas dolomíticas e ao seu potencial de degradação por ação dos sulfatos.

Segundo Coultrone et al. (2008) a alta alcalinidade resultante da dissolução de hidróxidos de cálcio e de magnésio promove a absorção de $\mathrm{SO}_{2}$ gasoso e a sua transformação em sulfatos, sendo que a este respeito o hidróxido de magnésio tem maior capacidade de absorção do que o hidróxido de cálcio. Lopez-Arce et al. (2009) referindo-se a um caso de estudo dum mosteiro em Espanha indicam que a degradação das argamassas ocorreu devido à formação de epsomite e hexahidrite em resultado da exposição à humidade e pela utilização de argamassas dolomíticas e de gesso.

Em sentido contrário, Montoya et al. (2003) apresentam resultados da caracterização de argamassas dolomíticas da Igreja de Santa Maria de Zamarce, em Espanha, e não referem a formação de sulfatos de magnésio, pese embora tenha sido incorporado gesso na formulação dessas argamassas. Já Berman, Frage e Tate (2003) ao realizarem um estudo sobre a ação da chuva ácida em argamassas dolomíticas concluíram que os teores de magnésio das amostras de lixiviados foram consistentemente baixos e que não houve a formação de eflorescências de sulfatos de magnésio, facto que atribuíram à baixa reatividade do hidróxido de magnésio. Por outro lado, Diekamp et al. (2012) referem que alteração das argamassas dolomíticas se inicia com a formação de gesso e que os sulfatos de magnésio só se formarão em estados mais avançados de exposição, devido à baixa solubilidade da magnesite. Ainda assim referem que são necessários longos períodos de humidade, uma vez que os ciclos de molhagem/secagem favorecem a formação de gesso. A formação de gesso à superfície da argamassa pode atuar como uma camada de proteção, impedindo a cristalização dos sulfatos de magnésio.

Ascais dolomíticas estão sujeitas à degradação, como aliás ocorre com qualquer outro tipo de ligante, não se podendo retirar uma conclusão imediata acerca da sua maior potencialidade de degradação em comparação, por exemplo, com as cais cálcicas. Um aspeto que parece ser consensual na comunidade técnica e científica é que as cais dolomíticas têm, em comparação com as cais cálcicas, melhor resistência à água (CHEVER; PAVÍA; HOWARD; 2010; ARIZZI; CULTRONE; 2012). Outras caraterísticas diferenciam as cais dolomíticas das cálcicas, que podem ter justificado a sua utilização em diversas situações, como se exemplificará de seguida com alguns exemplos de monumentos portugueses.

\section{Cal dolomítica em monumentos em Portugal}

O conhecimento do desempenho de argamassas de cal, particularmente de cais dolomíticas, no edificado construído é escasso. Na bibliografia encontram-se algumas poucas descrições sobre a utilização da cal dolomítica, e as que existem referem-se a estudos de caraterização de argamassas de monumentos históricos em países como a Áustria, Itália, Inglaterra e Espanha. Em Portugal existem vários afloramentos de calcários dolomíticos, sobretudo na região do Alentejo, mas também na região Norte, Centro, Lisboa e Algarve (MANUPELLA; BALACÓ MOREIRA; LUÍSA ROMÃO, 1981). Apesar desta distribuição pelo território de Portugal Continental, pouco é ainda conhecido acerca da utilização da cal dolomítica no edificado português.

Um dos primeiros casos estudados em Portugal de argamassas de cal dolomíticas (SANTOS SILVA et al., 2010) foi o da Igreja de Santa Maria de Évora, ou Catedral de Évora (Figura 1a). Esta Catedral está classificada como Património Mundial da Humanidade e está localizada na cidade histórica de Évora, na região Alentejo. A Catedral tem um estilo românico-gótico com forte influência de ordens cisterciense e mendicante, estando a sua construção situada entre os séculos XII e XIII. Como outros edifícios deste tipo, após o período de construção, a Catedral de Évora sofreu trabalhos de restauro e vários incrementos que refletiam o poder financeiro de um determinado período. Uma das maiores intervenções de que há registo foi realizada no século XVI, em que houve a substituição de vários rebocos e a colocação do cadeiral de madeira de carvalho no coro-alto. Desde o início do milénio que a Catedral tem vindo a sofrer obras de conservação e restauro, nomedamente de conservação da pedra do zimbório. Em 2005, e no âmbito dum projeto de investigação (Projeto FCT CATHEDRAL - POCI/HEC/57915/2004), foram recolhidas argamassas de vários locais da Catedral com o objetivo principal de proceder à sua caracterização e, entre outros aspetos, fornecer informações sobre o estado de conservação desses materiais.

As análises das argamassas da Catedral de Évora evidenciaram a presença dum ligante dolomítico, e que se verificou estar associado à grande intervenção realizada no monumento no século XVI. De referir que as argamassas encontravamse, em geral, em bom estado de conservação, 
embora em alguns locais existissem sinais de terem estado sujeitas à ação da água (Figura 1b). Um dos aspetos interessantes associados a estas argamassas foi a presença do composto hidromagnesite (Figura 2), sobretudo nas amostras provenientes de paredes viradas a norte e, portanto, mais expostas à humidade (ADRIANO et al., 2007). A hidromagnesite é um composto típico de cais dolomíticas sujeitas a ambiente húmido, composto esse que está também associado a argamassas com boas características mecânicas (DHEILLY et al., 1999).

Figura 1 - Imagens da Sé Catedral de Évora (Portugal)

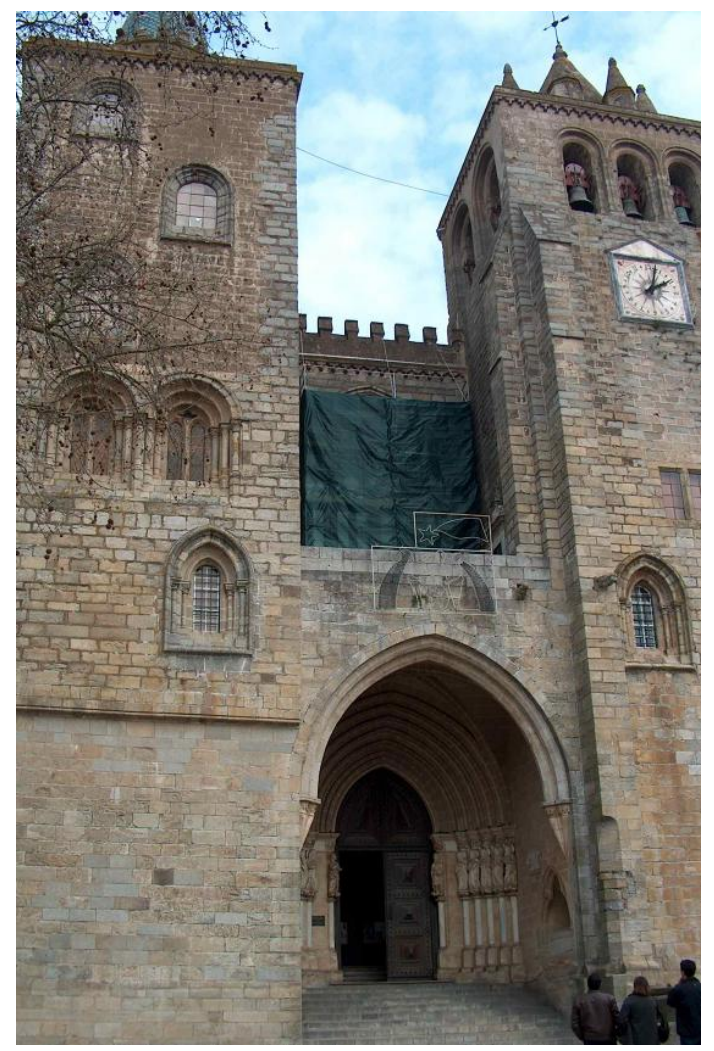

(a) Exterior

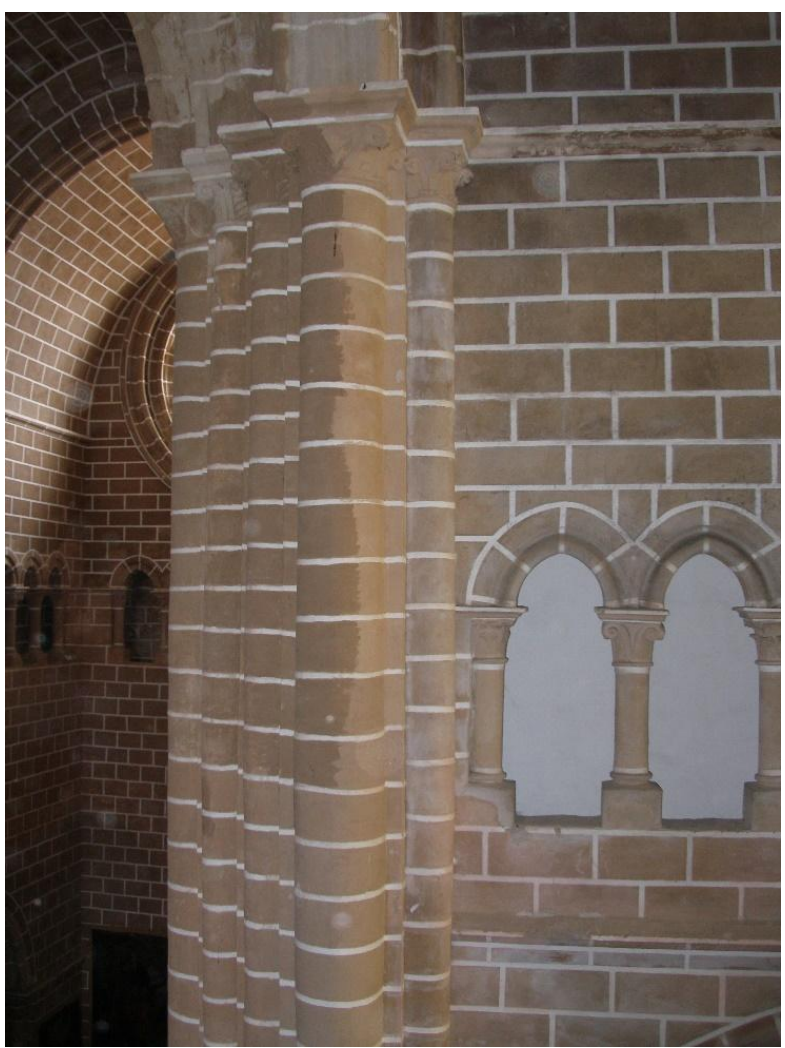

(b) Interior

Figura 2 - (a) Imagem ao microscópio eletrónico de varrimento (MEV) dum poro numa argamassa de cal dolomítica parcialmente recoberto por cristais de hidromagnesite; e (b) Espetro correspondente aos cristais no poro em (a) e que foi obtido por espectroscopia de raios $X$ por dispersão de energia (EDS)
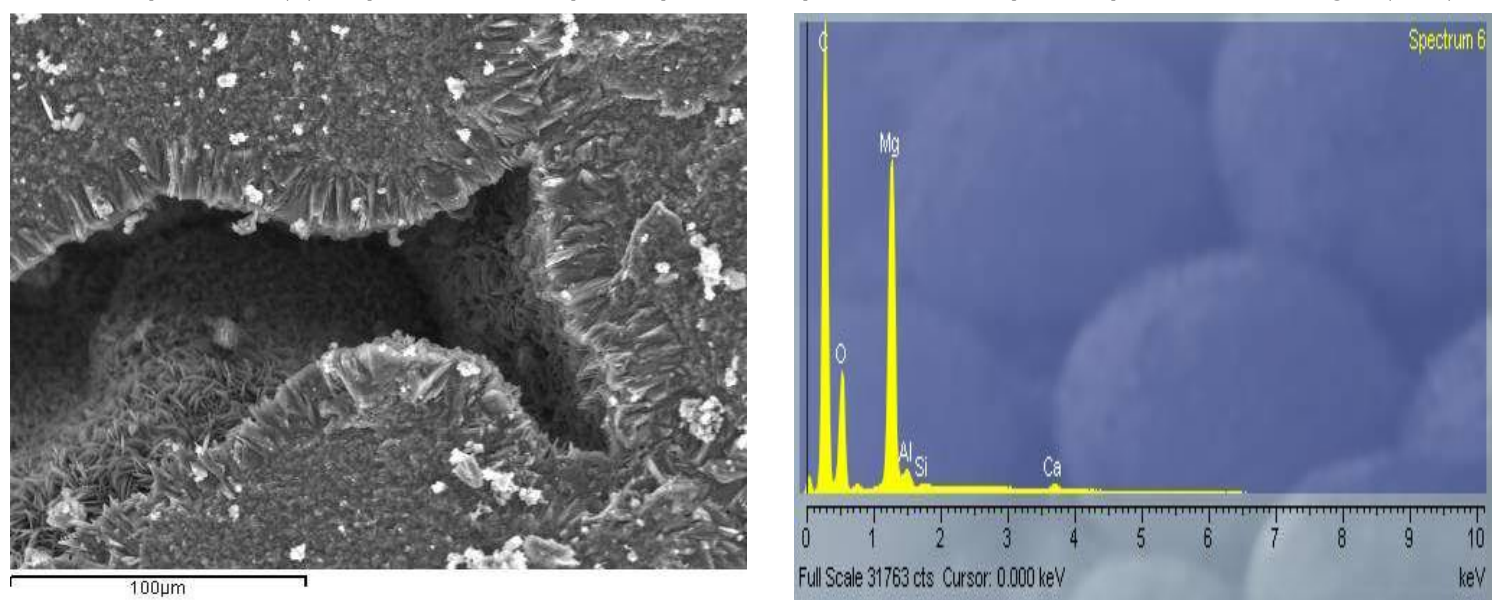
Outro exemplo, e descoberto mais recentemente, que atesta a presença de cais dolomíticas em Portugal, é o Forte de Nossa Senhora da Graça (Figura 3), localizado a norte da cidade de Elvas, no Alentejo (SANTOS SILVA et al., 2016). Este Forte foi listado como Património Nacional em 1910 e Património da Humanidade pela UNESCO em 2012. Obra-prima da arquitetura militar do século XVIII, é considerado um dos maiores símbolos das fortalezas abaluartadas do mundo. Dentro da sua indicação pela UNESCO como Património Mundial foi implementado um plano de conservação e restauro que envolveu a caracterização detalhada dos materiais utilizados na sua construção. A construção do Forte usou pedras e sobras de minas terrestres abertas na massa rochosa da montanha, bem como outros materiais existentes nas proximidades do local de construção, como areia e materiais cerâmicos. Para apoiar o plano de restauro foi implementado um plano de intervenção abrangente, tendo a caracterização das argamassas de revestimento e de juntas do Forte evidenciado, apesar de terem sido formuladas com diferentes traços, a presença dum ligante dolomítico.

Um aspeto interessante das cais dolomíticas, e que poderá justificar a sua durabilidade e resistência mesmo em condições de elevada humidade, é a sua capacidade para promoverem uma autoconsolidação. Esse processo é originado pela dissolução e recristalização das fases magnesianas do ligante. Segundo Lubelli, Nijland e Van Hees (2011) o processo de auto-consolidação em argamassas de cal é promovido pela água que dissolve os compostos do ligante e posteriormente os transporta, de zonas ricas no ligante, para zonas porosas e fissuradas na argamassa, contribuindo assim para o preenchimento dessas zonas (Figura 4).

As argamassas do Forte de Nossa Senhora da Graça (Figura 5), em Elvas, apesar de terem alguma colonização biológica, não apresentaram outros sinais de degradação, nomeadamente devido à formação de produtos de degradação química, como de sulfatos de magnésio. Os resultados dos ensaios físicos e mecânicos realizados comprovaram que as argamassas estão em bom estado de conservação, o que atesta o cuidado colocado na escolha de materiais e de execução na construção desta estrutura (SANTOS SILVA et al., 2016).

Estes dois exemplos de monumentos em Portugal são indicadores da resistência das argamassas antigas de cal dolomítica. Pese embora este desempenho, a utilização da cal dolomítica tem gerado muitos receios na comunidade técnica e científica. Devido a estas razões, vários investigadores têm vindo nos últimos anos a estudar em laboratório as características físicas e mecânicas de diferentes argamassas dolomíticas.

Figura 3 - Imagens do Forte Nossa Senhora da Graça, em Elvas

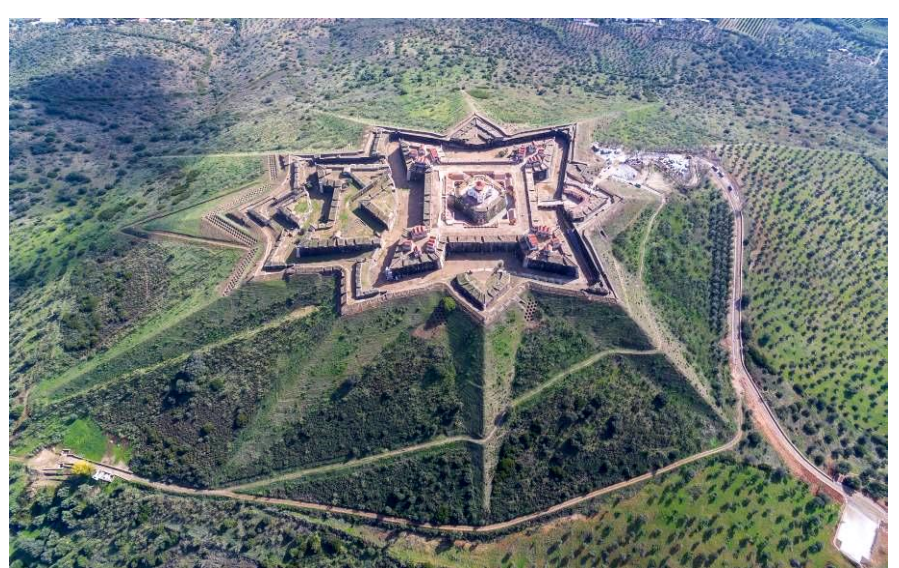

(a) Vista área*

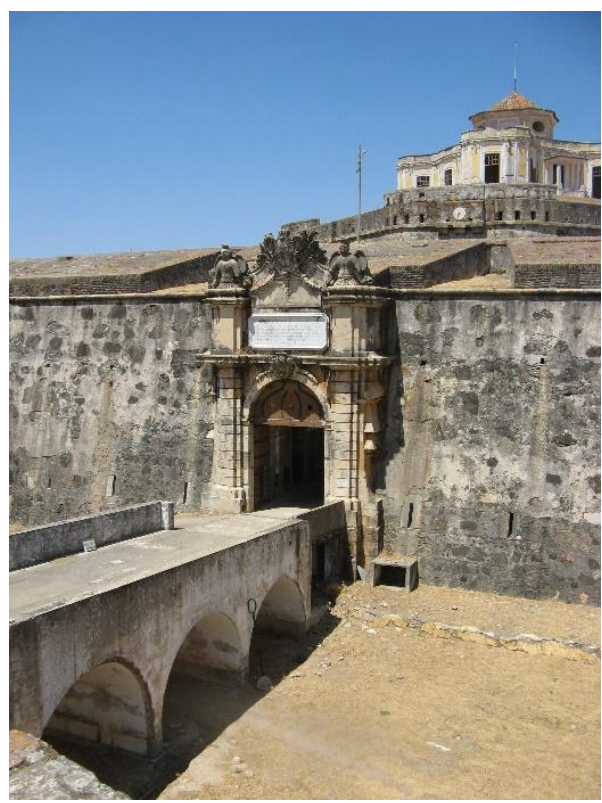

(b) Portal de entrada

Fonte: *Santos Silva et al. (2016). 
Figura 4 - Imagens ao MEV duma argamassa dolomítica onde são visíveis cristais de neoformação de hidromagnesite a preencherem zonas porosas na pasta

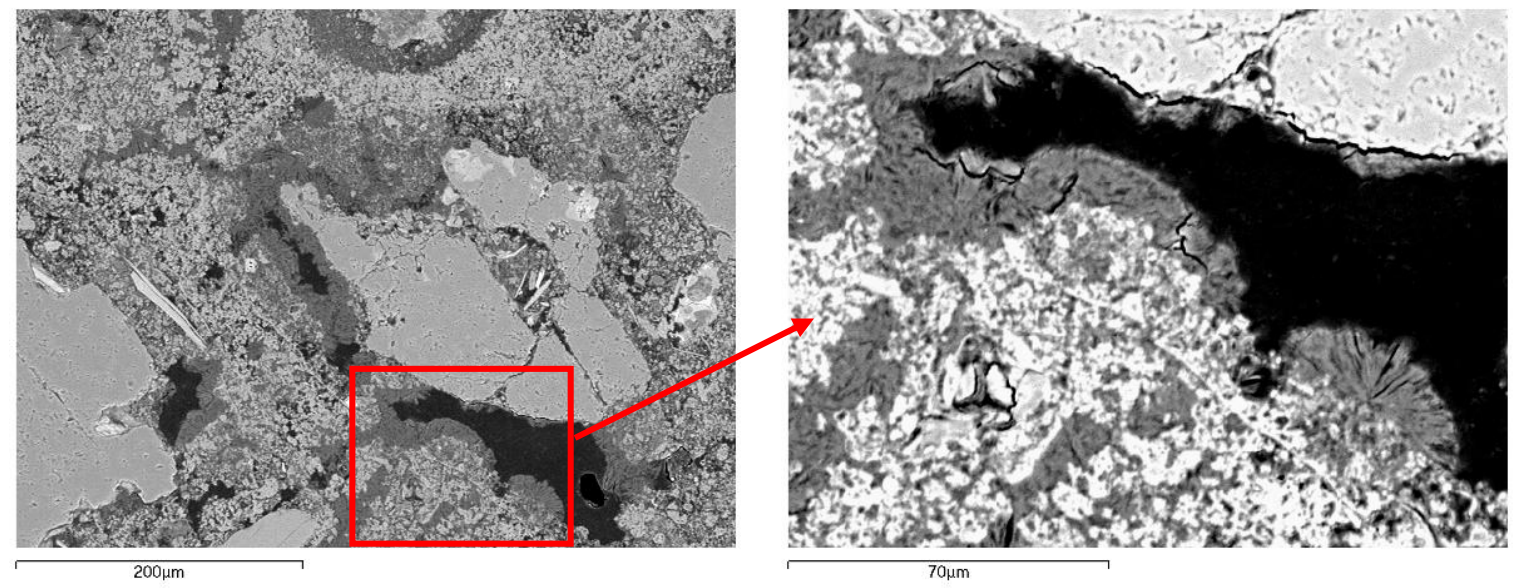

Figura 5 - (a) Imagem ao MEV da estratigrafia duma argamassa dolomítica; (b), (c) e (d) Mapas de raios X obtidos por EDS e correspondentes à imagem em (a), respetivamente dos elementos silício (Si), cálcio (Ca) e magnésio $(\mathrm{Mg})$

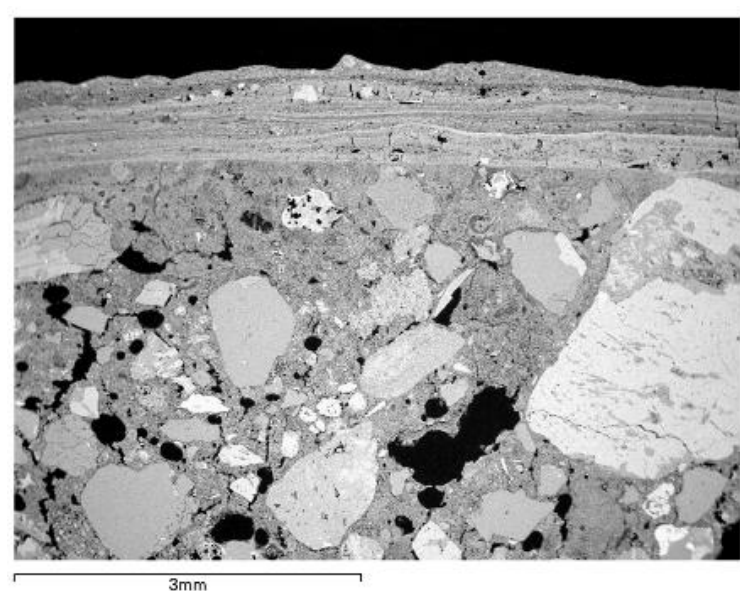

(a)

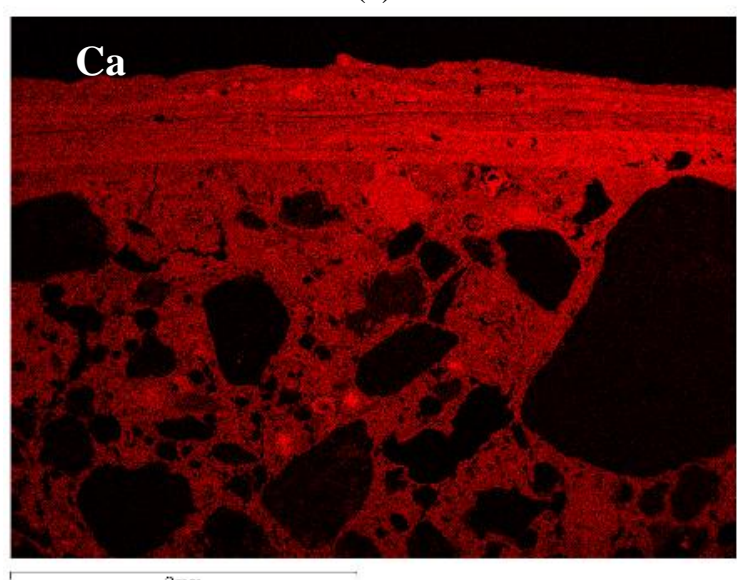

(c)

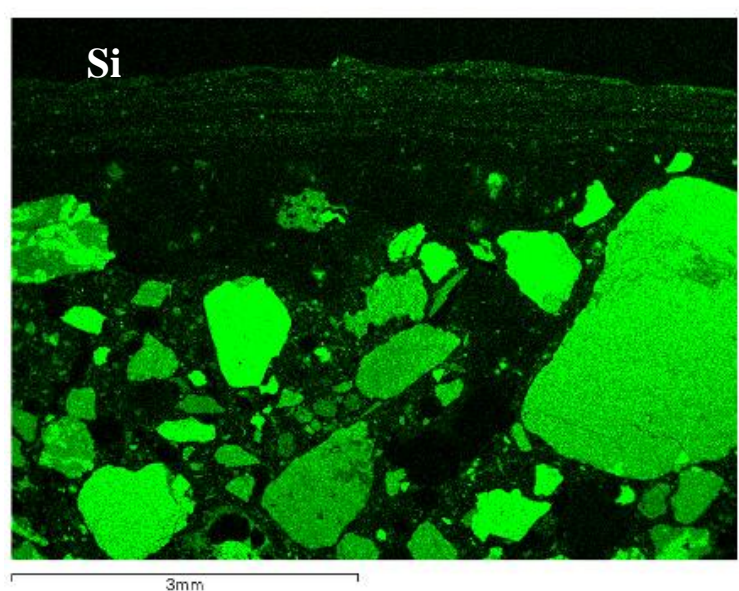

(b)

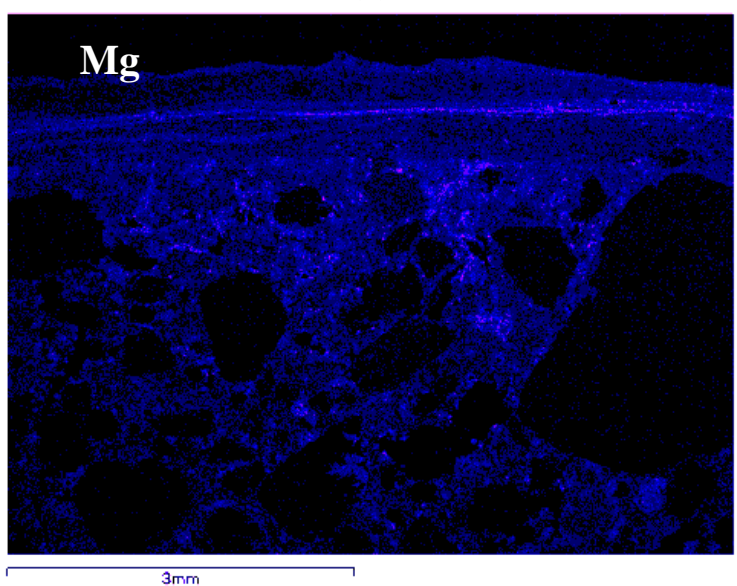

(d) 


\section{Características físicas e mecânicas das cais dolomíticas}

As cais dolomíticas são produzidas a partir de calcários magnesianos ou dolomíticos e cujo teor em magnésio pode variar bastante. A Norma Europeia EN 459-1 (INSTITUTO..., 2011) estabeleceu um conjunto de requisitos químicos (Tabela 2), de forma a classificar estas cais com base essencialmente nos teores que apresentam dos óxidos de cálcio $(\mathrm{CaO})$ e de magnésio $(\mathrm{MgO})$.

O teor em magnésio da cal dolomítica tem segundo Chever, Pavía e Howard (2010) uma influência marcante no desempenho destas cais. Estes autores indicam que existe uma relação direta entre o teor de magnésio e os valores de resistência à compressão e à flexão, isto é, àmedida que aumenta o teor de magnésio aumentam estas duas propriedades mecânicas. Este aspeto poderá assim explicar alguns resultados contraditórios na literatura em termos do desempenho das cais dolomíticas.

As características físicas e mecânicas das cais dolomíticas são quase sempre comparadas com as obtidas por cais cálcicas. Também neste particular não existe um consenso generalizado na bibliografia.
Em termos de absorção de água por capilaridade os dados encontrados na literatura são unânimes em considerar que as cais dolomíticas têm melhor comportamento do que o das cálcicas. Vinagre (2015) demonstrou (Figura 6) que as argamassas cálcicas, independentemente do traço utilizado, apresentam maior absorção de água do que argamassas dolomíticas (coeficiente de capilaridade aos 28 dias de 2,11 versus 1,14 $\mathrm{kg} /\left(\mathrm{m}^{2} \mathrm{~min}^{1 / 2}\right)$, isto é, cálcicas versus dolomíticas). Segundo Chever, Pavía e Howard (2010) este comportamento permite que as argamassas dolomíticas tenham um bom desempenho em locais húmidos.

Já em termos de resistências mecânicas os resultados não são tão consensuais. Segundo Arizzi e Cultrone (2012) a cal dolomítica tem valores de resistência à tração e à compressão inferiores aos da cálcica, atribuindo esse comportamento à existência de maior retração na cal dolomítica. No entanto, estes resultados não são comprovados pela maioria dos investigadores como, por exemplo, Dheilly et al. (1999), Chever,Pavía e Howard (2010) ou Vinagre (2015) (Figura 7). Esta discrepância de resultados pode, por um lado, ser devida à composição da cal dolomítica empregue, e por outro lado às condições de fabrico e cura dessas argamassas.

Tabela 2 - Requisitos químicos para a cal dolomítica

\begin{tabular}{c|c|c|c|c}
\hline Tipo de cal dolomítica & $\mathbf{C a O}+\mathbf{M g O}$ & $\mathbf{M g O}$ & $\mathbf{C O}_{\mathbf{2}}$ & $\mathbf{S O}_{\mathbf{3}}$ \\
\hline DL 90-30 & $\geq 90$ & $\geq 30$ & $\leq 6$ & $\leq 2$ \\
DL 90-5 & $\geq 90$ & $\geq 5$ & $\leq 6$ & $\leq 2$ \\
DL 85-30 & $\geq 85$ & $\geq 30$ & $\leq 9$ & $\leq 2$ \\
DL 80-5 & $\geq 80$ & $\geq 5$ & $\leq 9$ & $\leq 2$ \\
\hline
\end{tabular}

Fonte: IPQ (INSTITUTO..., 2011).

Figura 6 - Curvas de absorção de água por capilaridade de argamassas de cal dolomítica (CD) e cálcica (CC) aos traços volumétricos de 1:2 e 1:3 cal hidratada em pó:areia natural siliciosa (VINAGRE, 2015). As cais empregues foram do tipo DL 80-5 e CL 90, designações segundo a norma EN 459-1 para uma cal dolomítica com $\mathrm{CaO}+\mathrm{MgO} \geq 80$ e $\mathrm{MgO}>5$, e cálcica com $\mathrm{CaO}+\mathrm{MgO} \geq 90$

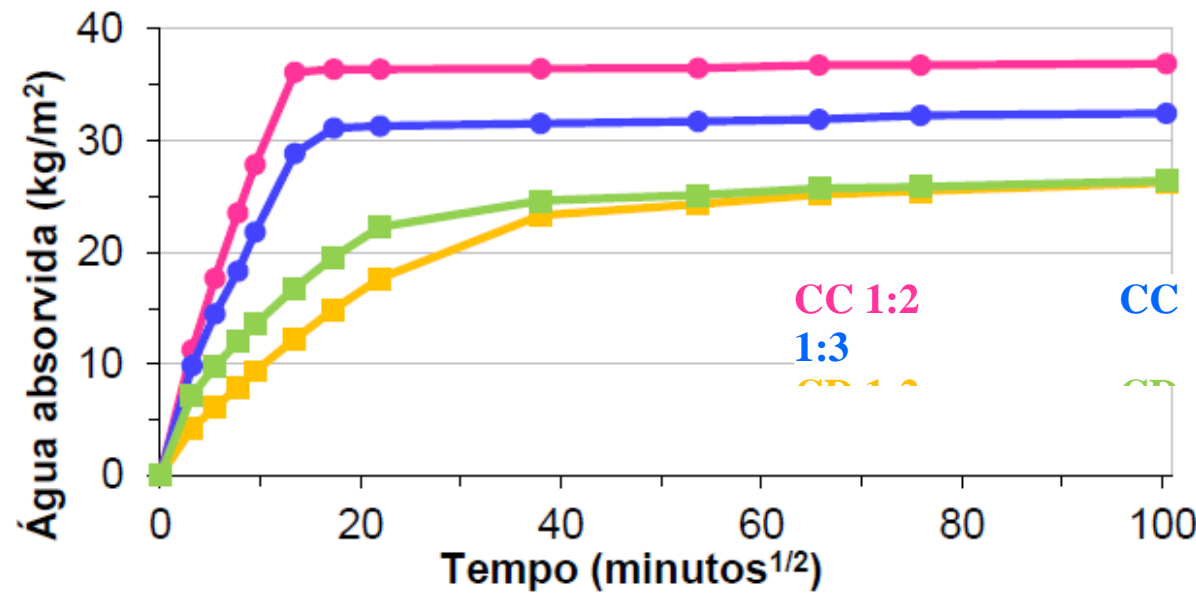


Segundo Chever, Pavía e Howard (2010), as argamassas de cal dolomítica podem atingir valores de resistência à compressão e à flexão da mesma ordem de grandeza que os obtidos com uma cal hidráulica natural do tipo NHL 2. A cal hidráulica natural é, de acordo com a Norma Europeia EN 459-1 (INSTITUTO..., 2011), uma cal produzida pela calcinação de calcários mais ou menos argilosos ou siliciosos e que não contém quaisquer aditivos, sendo classificada como NHL 2, NHL 3,5 ou NHL 5 consoante o valor de $\mathrm{Ca}(\mathrm{OH})_{2}$ disponível e o valor de resistência à compressão caraterístico determinado aos 28 dias, sendo que para a NHL 2 este último valor deve ser $\geq 2$ e $\leq 7 \mathrm{MPa}$.

O facto de as resistências mecânicas nas argamassas de cal dolomítica serem superiores, em geral, aos da cal cálcica tem sido atribuído à sua diferente microestrutura. De acordo com Chever, Pavía e Howard (2010) as argamassas de cal dolomítica têm uma estrutura porosa em que predominam poros de maior dimensão $(>5 \mu \mathrm{m})$, o que segundo Lanas et al. (2006) permite que a carbonatação nestas argamassas ocorra de forma mais rápida e completa.

Para além da microestrutura, os tipos de compostos de magnésio formados no endurecimento das argamassas dolomíticas também têm uma influência na resistência final que é obtida. Neste particular, a formação de hidromagnesite e de fases amorfas ou mal cristalizadas de compostos de magnésio tem sido apontada por vários autores como um dos fatores que contribui para a boa resistência mecânica destas argamassas (MONTOYA et al., 2003; DIEKAMP et al., 2008).

\section{Conclusões}

A cal dolomítica é usada desde a antiguidade, com vários exemplos em Portugal e no estrangeiro que atestam as suas qualidades em construções antigas.

$\mathrm{Na}$ viragem do século $\mathrm{XX}$ receios da sua alterabilidade em presença de atmosferas ricas em $\mathrm{SO}_{2}$ fizeram com que o seu uso fosse questionado. No entanto, alguns estudos (BERMAN; FRAGE; TATE, 2003) demonstraram que as cais dolomíticas são bastante resistentes à alteração por sulfatos, nomeadamente quando expostas à ação de chuvas ácidas. Por outro lado, os resultados contraditórios que existem na literatura acerca das propriedades mecânicas das argamassas dolomíticas parecem, segundo Chever, Pavía e Howard (2010), estar associados ao teor em magnésio nestas cais. Segundo estes autores, as cais dolomíticas com teores em magnésio mais elevados produzirão argamassas com resistência à compressão e à flexão mais elevadas, e o oposto quando os teores de magnésio forem mais baixos.

Figura 7 - Resistência à compressão de argamassas de cal cálcica (CC) e dolomítica (CD) ao traço volumétrico de 1:3 e 1:2 (cal hidratada em pó:areia natural siliciosa). As cais empregues foram do tipo DL 80-5 e CL 90, respetivamente
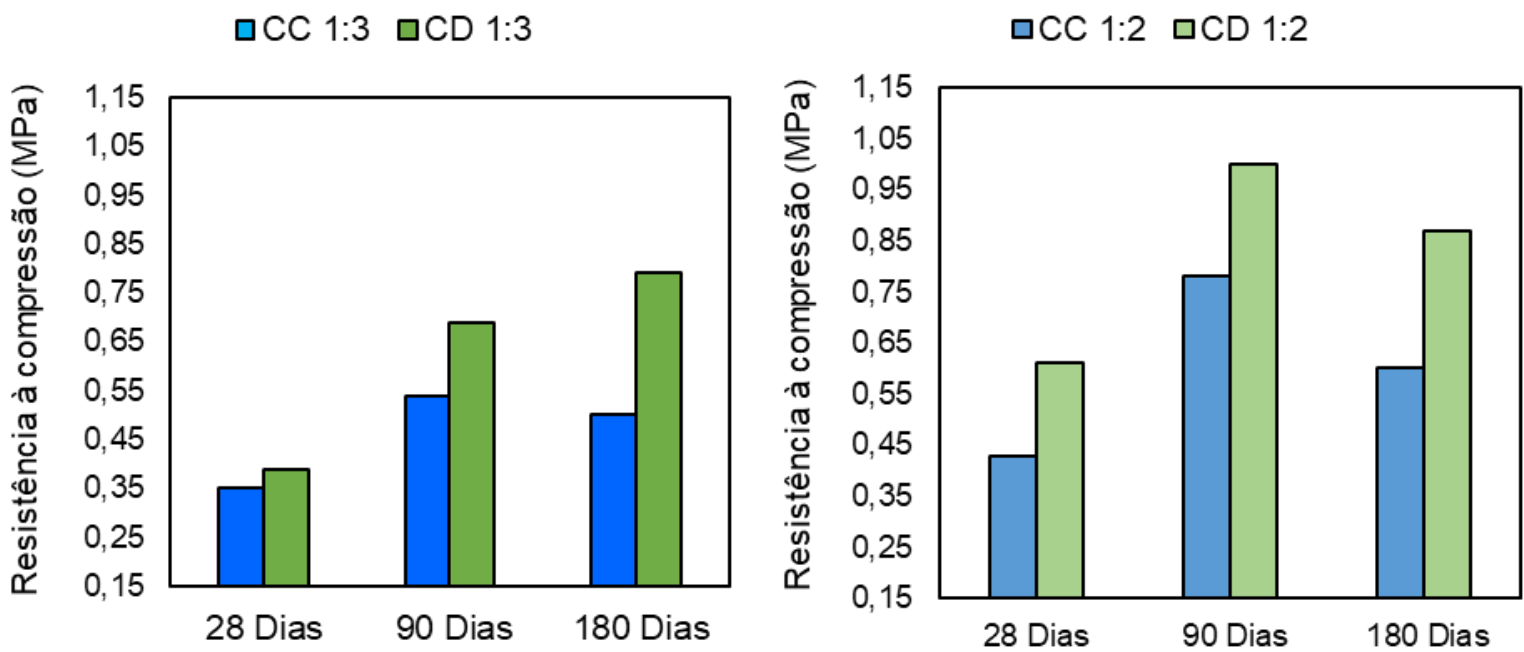

Fonte: Vinagre (2015). 
Neste artigo são referidos resultados de caracterização de argamassas de cal dolomítica que indicam que estas, quando devidamente formuladas, atingem características mecânicas similares a uma cal hidráulica natural do tipo NHL 2 (resistência à compressão aos 28 dias $\geq 2 \mathrm{MPa}$ ). São ainda apresentados resultados de argamassas formuladas ao traço volumétrico de cal:areia de 1:2 e 1:3 em que ficou demonstrado que as argamassas de cal dolomítica têm melhor comportamento mecânico e físico do que as correspondentes argamassas com cal cálcica. Já a análise de argamassas dolomíticas antigas mostra que nas argamassas dolomíticas ocorre com frequência a precipitação de compostos hidratados de magnésio nas zonas porosas da pasta do ligante, compostos esses que de acordo com Lubelli, Nijland e Van Hees (2011) são mais insolúveis que alguns compostos de cálcio. A presença de compostos recristalizados de magnésio nas argamassas de cal dolomítica pode estar assim na origem da sua maior resistência, nomeadamente em comparação com as de cal cálcica, sendo esse comportamento explicado pela capacidade de autoconsolidação dos compostos de magnésio.

Com base no exposto, conclui-se que as cais dolomíticas produzem argamassas com características físicas e mecânicas superiores às de argamassas de cal cálcica, sendo particularmente interessantes para usos em alvenaria em ambientes com alguma humidade (CHEVER; PAVÍA; HOWARD, 2010), justificando-se por isso a sua maior utilização quer em construção nova, como em reparação e restauração de construções históricas.

\section{Referências}

ADRIANO, P. et al. Microscopic Characterisation of Old Mortars From the Santa Maria Church in Évora. In: EUROSEMINAR ON MICROSCOPY APPLIED TO BUILDING MATERIALS, 11., Porto, 2007. Proceedings... Porto, 2007.

ARIZZI, A.; CULTRONE, G. The Difference in BehaviourBetweenCalcitic and Dolomitic Lime Mortars Set Under Dry Conditions: the relationship between textural and physicalmechanical properties. Cement and Concrete Research, v. 42, p. 818-826, 2012.

BERMAN, S.; FRAGE, D.F.; TATE, M.J. The Effect of Acid Rain on Magnesium Hydroxide Contained in Cement-Lime Mortar. Masonry, 2003.

CHEVER, L.; PAVÍA, S.; HOWARD, R. Physical Properties of Magnesian Lime Mortars. Materials and Structures, v. 43, p. 283-296, 2010.
COULTRONE, G. et al. Sulfation of Calcitic and Dolomitic Lime Mortars in the Presence of Diesel Particulate Matter. Environmental Geology, v. 56, p. 741-752, 2008.

DHEILLY, R. M. et al. Hydromagnesite Development in Magnesian Lime Mortars. Materials Science and Engineering, v. 268, p. 127-131, 1999.

DIEKAMP, A. et al. Dolomitic Lime Mortar and the Impact of $\mathrm{SO}_{2}$-Pollution. In:

INTERNATIONAL CONGRESS ON THE DETERIORATION AND CONSERVATION OF STONE, 12., New York, 2012. Proceedings... New York, 2012.

DIEKAMP, A. et al. Dolomitic Lime Mortar: a commonly used building material for medieval buildings in Western Austria and Northern Italy. In: INTERNATIONAL CONGRESS ON DETERIORATION AND CONSERVATION OF STONE, 11., Torun, 2008. Proceedings... Torun, 2008.

DIEKAMP, A.; KONZETT, J.; MIRWALD, P. W . Mineralogical Characterization of Historic Mortars From Tyrol, Austria and South-Tyrol, Italy.In: HISTORIC MORTARS CONFERENCE, 1.,Lisbon, 2008. Proceedings... Lisbon, 2008.

GLEIZE, P. J. P. et al.Characterization of Historical Mortars From Santa Catarina (Brazil). Cement and Concrete Composites, v. 31, p. 342346, 2009.

HARTSHORN, H. Dolomitic Lime Mortars: carbonation complications and susceptibility to acidic sulfates. 2012. $193 \mathrm{f}$. Tese (Master of Science in Historic Preservation) - Columbia University, 2012.

INSTITUTO PORTUGUÊS DA QUALIDADE. NP EN 459-1: cal de construção: parte 1: definições, especificações e critérios de conformidade.Caparica, 2011.

LANAS, J. et al. Mechanical Properties of Masonry Repair Dolomitic Lime-Based Mortars. Cement and Concrete Research, v. 36, p. 951960, 2006.

LOPEZ-ARCE, P. et al. Deterioration of Dolostone by Magnesium Sulphate Salt: an example of incompatible building materials at Bonaval Monastery, Spain. Construction and Building Materials, v. 23, p. 846-855, 2009.

LUBELLI, B.; NIJLAND, T.G.; VAN HEES, R. P. J. Simulation of Self-Healing of Dolomitic Mortar. In: EUROSEMINAR ON MICROSCOPY APPLIED TO BUILDING MATERIALS, 13., Ljubljana, 2011. Proceedings... Ljubljana, 2011. 
MANUPELLA, G.; BALACÓ MOREIRA, J. C.; LUÍSA ROMÃO, M. Panorama dos Dolomitos e Calcários Dolomiticos PORTUGUESES. Boletim de Minas, v. 17, n. 4, 1981.

MARAVELAKI-KALAITZAKI, P.; BAKOLAS, A.; MOROPOULOU, A. Physico-Chemical Study of Cretan Ancient mortars. Cement and Concrete Research, v. 33, p. 651-661, 2003.

MONTOYA, C. et al. Study of Ancient Dolomitic Mortars of the Church of Santa María de Zamarce in Navarra (Spain): comparison with simulated standards. ThermochimicaActa, v. 398, p. 107- 122, 2003.

PANDA, A.; MISRA, M. K. Traditional Methods of Mollusc Shell Collection For Lime Preparation in East Coast of India. Indian Journal of Traditional Knowledge, v. 64, p. 549-558, 2007.

PAPAYANNI, I. Design and Manufature of Repair Mortars For Interventions on Monuments and Historical Buildings. In: WORKSHOP REPAIR MORTARS FOR HISTORIC MASONRY, Delft, 2005. Proceedings... 2005.

SANTOS SILVA, A. et al. Characterization of Historical Mortars from Alentejo's Religious Buildings. International Journal of Architectural Heritage, v. 4, n. 2, p. 183-154, 2010.

SANTOS SILVA, A. et al. Characterization of Mortars From the Fort of NossaSenhora da Graça, Elvas (Portugal) to Support the Conservation of the Monument. In: HISTORICAL MORTARS CONFERENCE, 4., Santorini, 2016.

Proceedings... Santorini, 2016.
VEIGA, M. R. et al.Methodologies For Characterisation and Repair of Mortars of Ancient Buildings. In: INTERNATIONAL SEMINAR HISTORICAL CONSTRUCTIONS, Guimarães, 2001. Proceedings... Guimarães, 2001.

VINAGRE, A. I. B. Estudo Comparativo Entre Argamassas de Cal Calcítica e de Cal

Dolomítica: características mecânicas, físicas, mineralógicas e microestruturais. Évora, 2015. 203 f. Tese (Mestrado em Engenharia Geológica) Universidade de Évora, Évora, 2015.

\section{Agradecimentos}

Agradece-se a disponibilização de ligantes pelas empresas Lusical e Calcical, à Fundação para a Ciência e Tecnologia (FCT) pelo seu apoio através do projeto PTDC/EPH-PAT/4684/2014: DBHERITAGE - Base de dados de materiais de construção com interesse histórico e patrimonial, e também ao Laboratório Nacional de Engenharia Civil (LNEC) pelo seu apoio através dos projetos DUR-HERITAGE - Durabilidade e caracterização de materiais com interesse histórico e PRESERVe - Preservação de revestimentos do património construído com valor cultural: identificação de riscos, contributo do saber tradicional e novos materiais para conservação e proteção. Agradecese também a Ana Vinagre, Rosário Veiga, Ana Rita Santos, Dora Santos, Paula Menezes, Dora Soares e Fátima Llera pela ajuda na campanha experimental e disponibilização de informação para a redação deste artigo.

Antonio Santos Silva

Departamento de Materiais | Laboratório Nacional de Engenharia Civil | Avenida do Brasil, 101 | Lisboa-Portugal | 1700-066 | Tel.: + (351) 21 844-3000 | E-mail: ssilva@lnec.pt

\author{
Revista Ambiente Construído \\ Associação Nacional de Tecnologia do Ambiente Construído \\ Av. Osvaldo Aranha, $99-3^{\circ}$ andar, Centro \\ Porto Alegre - RS - Brasil \\ CEP $90035-190$ \\ Telefone: +55 (51) 3308-4084 \\ Fax: +55 (51) 3308-4054 \\ www.seer.ufrgs.br/ambienteconstruido \\ E-mail: ambienteconstruido@ufrgs.br
}

